\title{
EL TEXTO LITERARIO A LA LUZ DE LA HERMENÉUTICA
}

\author{
Antonio GARRIDO DOMÍNGUEZ
}

\author{
Universidad Complutense
}

1. El eclipse del interés por la forma ha provocado, como suele ocurrir en los cambios de paradigma, un desplazamiento del centro de atención hacia otros aspectos o niveles del objeto de estudio; en este caso los esfuerzos de los estudiosos se han polarizado, siguiendo un movimiento pendular, en torno al sentido y, en suma, la interpretación de los textos literarios. Esta orientación se ha visto potenciada por el predominio de modelos teórico-literarios muy diversos que van desde la semiótica y la pragmática hasta la poética de lo imaginario y, por supuesto, la hermenéutica; corrientes, en suma, que, en mayor o menor medida, se mueven en el ámbito de los enfoques comunicativos y tienen al receptor en su punto de mira. Lo cierto es que, a la vista de la incuestionable densidad semántica de los textos, en literatura más que de sentido habría que hablar de sentidos. R. Barthes (1967: 293-299) tiene razón, en su polémica con la crítica académica (y, específicamente, con R. Picard) cuando afirma que el sentido constituye, por naturaleza, una realidad evanescente. También la tienen indudablemente G. Steiner y P. Ricoeur desde sus respectivas posturas de defensa a ultranza del sentido contra todo tipo de relativismos y continuos aplazamientos del significado; todo ello sin negar que, como afirma Gracián, la palabra poética es como la hidra: 
su sentido es, en principio, inagotable y de los organismos aparentemente muertos surgen de continuo nuevos brotes que rejuvenecen esplendores perdidos y los potencian.

En torno a estas cuestiones gira gran parte de los esfuerzos que se desarrollan, aunque de forma no exclusiva, en el campo de la teoría literaria; puede muy bien afirmarse que se extienden al conjunto de las ciencias humanas y, de manera muy especial, a la Hermenéutica en sus diferentes versiones. Con todo, no conviene olvidar, como ocurre tan frecuentemente, que en literatura el sentido se vincula inevitablemente a la realidad de los textos y que, por consiguiente, cualquier intento de esclarecimiento de este asunto pasa inevitablemente por ellos. Es algo que no escapó a la habitual perspicacia, entre otros, de los grandes representantes del estructuralismo lingüístico y que, desde otra perspectiva, defiende también Bajtín. En efecto, autores como Bloomfield, Hjemslev, Harris - y, sobre todo, Benveniste- postulan en las postrimerías del gran movimiento estructuralista la inesquivable necesidad del ir más allá de la oración por razones tanto sintácticas como, principalmente, semánticas, ya que, a diferencia de la forma, el sentido ofrece una gran resistencia a la segmentación. Dicho de otro modo: el sentido se constituye generalmente en un nivel supraoracional y, por consiguiente, la unidad de análisis no puede situarse en un plano inferior so pena de echar a perder la verdadera unidad comunicativa. Benveniste (1977: 82-91) habla consecuentemente de una translingüística, disciplina que se ocuparía del análisis de esta unidad discursiva superior a la oración, a la que denomina discurso o enunciado.

Tanto Bajtín como la Escuela de Tartu aportan enfoques muy novedosos y enriquecedores sobre la noción de texto o equivalentes y su aplicación al análisis de los textos literarios o culturales. En Bajtín (1982: 248-293)habría que destacar conceptos de tanta relevancia en el análisis de los textos como los de dialogismo, intertextualidad o plurilingüismo, aunque para el objeto de este trabajo es preciso reconocer la importancia del concepto de texto - específicamente, el de la novela - como ideologema; esto es, como realidad impregnada de sentido y vinculable por tanto a determinados grupos sociales. Destaca, por lo demás, la concepción del texto o enunciado como unidad real de la comunicación frente a las unidades de la lengua, palabra y oración, que no son más que el material del enunciado y que sólo se cargan de sentido en el marco de un contexto comunicativo específico (y sirviendo, por tanto, a las intenciones expresivas del hablante). Frente a la poética formalista Bajtín (1978: 75-94) argumenta que el soporte y horizonte último del texto es de naturaleza inevitablemente socio-ideológica y, por consiguiente, en su constitución pesan no sólo las inten- 
ciones del enunciador, sino, sobre todo, el objeto del enunciado y la visión del mundo de quien se expresa (además de las posibilidades expresivas del código).

Interesante es sin duda la propuesta sobre el texto de I. Lotman, formulada desde los presupuestos de la Semiótica de la Cultura. Para el autor, el texto es, en primer lugar, un artilugio semiótico cuyo objetivo último es la transmisión de información sobre el mundo o, en términos más técnicos, la elaboración y almacenamiento de imágenes-modelos de la realidad. Desde esta perspectiva cultural texto es, por consiguiente, el de naturaleza verbal - poema, novela, artículo periodístico, etc. - pero también la composición musical o pictórica, la escultura, el filme, etc. En esto se pone de manifiesto que la memoria de la humanidad es de naturaleza textual.

Centrándonos en el texto específicamente literario, son varios los rasgos que, según Lotman (1970: 70-73), lo caracterizan y diversas las funciones que desempeña. Entre los primeros cabe destacar su constitución a la luz de un modelo sígnico —expresión-, su carácter cerrado —delimitación: sus límites ejercen un cometido modelizador sobre el propio texto- y, finalmente, su fuerte estructuración, fruto de la intervención en su formación de múltiples códigos. Este último rasgo reviste una enorme importancia, ya que la densidad semántica del texto crece en proporción directa al número de códigos presentes hasta el punto de que puede muy bien afirmarse que no existen elementos semánticamente neutros dentro del texto; todos, incluso los de índole más externa (como los sonidos ) se cargan de significado y contribuyen a una transmisión más eficaz del mensaje. Así, pues, a la luz de esos rasgos el texto se presenta como un mecanismo privilegiado en cuanto al volumen de información que puede almacenar y esto es algo propio, por lo demás, de los sistemas modelizantes secundarios (Lotman, 1970: 20; Lotman y Uspensky, 1979: 67-92).

Las funciones que se le atribuyen permiten completar la definición lotmaniana de texto. El primer cometido - la función comunicativa- es el que se deriva de su naturaleza sígnica y tiene que ver con el papel que se le asigna como mediador entre un emisor y un receptor. El segundo, alude al texto no sólo como asiento del sentido, sino, sobre todo, como generador de nuevos sentidos (presumiblemente no previstos), hecho que pone de manifiesto el carácter creativo del texto desde un punto de vista semántico (expresión, por lo demás, de su activa e incesante actividad renovadora). El último de los cometidos se refiere a la capacidad nemotécnica del texto, esto es, a la facultad que posee de restaurar el recuerdo y salvar del olvido estratos de la historia más o menos alejados. Por esta razón los textos funcionan como símbolos integrales y este hecho, constitu- 
ye otro de los soportes hermenéuticos del texto. Para el logro de estos objetivos el texto debe estar en contacto con sus receptores — sólo así se justifica su capacidad generadora de sentido- y con el medio habitual de los signos: la semiosfera (Lotman, 1996: 86-90, 94-100). En palabras del autor:

A la luz de lo dicho, el texto se presenta ante nosotros no como la realización de un mensaje en un solo lenguaje cualquiera, sino como un complejo dispositivo que guarda varios códigos, capaz de transformar los mensajes recibidos y de generar nuevos mensajes, un generador informacional que posee rasgos de una persona con un intelecto altamente desarrollado. En relación con esto cambia la idea que se tenía sobre la relación entre el consumidor y el texto. En vez de la fórmula «el consumidor descifra el texto», es posible una más exacta: «el consumidor trata con el texto». Entra en contacto con él

(Lotman, 1996: 82).

Algunas de las afirmaciones de Lotman sitúan la noción de texto en el umbral de la teoría de los modelos; se trata, específicamente, de la que alude al texto como imagen finita de un mundo infinito. De acuerdo con este aserto el texto se constituye siguiendo, en, primer lugar, el modelo de la lengua natural y, en segundo lugar, llevando a cabo un proceso de semiotización y semantización (Lotman, 1970: 17-37, 47ss; Mignolo, 1986: 231-243). La especial densidad significativa del texto y su naturaleza esencialmente simbólica convierten el texto en un objeto hermenéutico en cuya decodificación intervienen decisivamente los variados códigos literarios y culturales.

Otro de los desarrollos importantes de la teoría del texto es la vinculación establecida por la Lingüística del Texto entre éste y la Teoría de la acción comunicativa. El texto pasa a ser considerado desde esta perspectiva un importante factor dinamizador de los procesos de interacción social; en términos de S.J.Schmidt (1973: 41-62, 147-154; 1997: 225-226), el texto es objeto de acciones empíricamente constatables como la producción, transmisión, recepción y procesado de una determinada información en el marco de una determinada sociedad, pero éste no es más que uno de los sentidos en los que se puede atribuir un carácter activo al texto. En cualquier caso, una de las mayores novedades de las gramáticas del texto es la consideración pragmática de los fenómenos linguísticos y, en lo que al texto literario se refiere, el señalamiento de los criterios o convenciones que facilitarán a los usuarios su identificación: la de polivalencia o densidad significativa y la ficcionalidad o reconocimiento de que los mundos de la literatura se rigen por una lógica específica. La decisión sobre la naturaleza literaria de un texto es un asunto que queda en manos de los receptores y, más específicamente, es una 
competencia de esa institución social llamada literatura que, según T.A. van Dijk (1981: 80ss; 1995: cps. VI-VII), constituye una de las acciones ritualizadas de una determinada sociedad. El texto - formado por una secuencia de frases semánticamente coherente- responde a una finalidad esencialmente comunicativa y ha de considerarse la plasmación de una cualidad diferencial constitutiva: la textualidad. El resorte del texto es siempre de naturaleza significativo-comunicativa y, de ahí, la importancia de un enfoque hermenéutico, además del semiótico, el sociológico, psicológico, etc. La comprensión de un texto es definida como la asignación de sentido a una sarta de signos.

Son precisamente dos conceptos de esta escuela - los de coherencia y cohesión, según U. Eco (1992: 121-125, 141, 156) los que permiten una fundamentación sólida de la interpretación; dicho en otros términos, es el respeto a los inalienables derechos del texto el que, sin negar por eso la posibilidad de la multiplicidad de lecturas a que puede prestarse, garantiza que el proceso hermenéutico transcurra por cauces no alejados de la objetividad y la sensatez. Habría que encontrar un equilibrio relativamente holgado entre la iniciativa del intérprete - perfectamente legitimado como modelo explicativo una vez que se han producido las respectivas hipertrofias del autor y del texto- y la fidelidad a la obra. Como se ha visto, el interés por el papel del lector aflora ya en los años '30 de la mano de R. Ingarden (1977: 86ss) y J. Mukarosky (2000: 127-203) y se aprecia, de manera más o menos una intensa según los casos, en el estructuralismo (especialmente, en los narratólogos franceses y angloamericanos, la Escuela de Tartu y los principales representantes de la Lingüística del Texto), pero no cristalizará de modo patente hasta el advenimiento de la Escuela de Constanza.

En efecto, la atención de la Estética de la Recepción se dirige, bien hacia la fenomenología de la lectura (W. Iser y las tareas del lector frente al texto ), bien hacia la relación históricamente variable —el 'diálogo' en términos gadamerianos- entre el texto y el lector (H.R. Jauss). En ambos casos el texto aparece como depositario de contenidos de gran densidad y destinatario principal de las actividades del receptor: en el caso de Iser (1987: 222-223) 'rellenando' sus inevitables vacíos informativos (a causa del esquematismo que le es constitutivo); en el de Jauss (1987: 59-85; 1967: 70-114) poniendo de manifiesto cómo, enfrentado a lectores de diferentes épocas, los sentidos del texto varían incluso sustancialmente. El interés por el sentido y el lector han hecho que los centros de atención de los representantes de la Estética de la Recepción y de la Hermenéutica terminaran por converger —al menos, parcialmente- y se intercambiaran conceptos e instrumentos de análisis. Es el caso de Jauss con respecto a Gadamer y de Ricoeur en relación con Iser. 
2. La noción de texto se ha visto enriquecida en los últimos tiempos (preferentemente) desde posiciones o corrientes centradas, bien en la recepción de los textos - el fenómeno de la lectura y la interpretación—, bien inspiradas en áreas de conocimiento o disciplinas ajenas, en principio, al mundo de la literatura. Entre las primeras cabe destacar las representadas por G. Steiner y U. Eco, principalmente. Las segundas se inscriben preponderantemente en el marco del pensamiento filosófico y se presentan - en algunos casos manifiestamente: P. Ricoeur- como alternativas ante la ausencia clamorosa de una disciplina encargada oficialmente de la interpretación de los textos literarios y de las reglas que han de velar por la validez del procedimiento. Se trata, obviamente, de la Hermenéutica.

2.1. Embarcado en una verdadera cruzada contra el relativismo interpretativo y el desinterés — cuando no negación — respecto del significado de los textos o productos manifestaciones artísticas (composición pictórica o musical, etc.), Steiner (1991: 18-68, 126ss, 169-202) reivindica la presencia de un algo en lo que decimos, esto es, de un sentido inscrito en el texto para ser experimentado y disfrutado por el lector. Así, pues, el texto funciona como depositario de un sentido - es este hecho el que justifica su existencia - al alcance de todo lector adecuadamente preparado para hacerse cargo de él. La protesta de Steiner se dirige, en primer término, contra los movimientos estructuralistas y postestructuralistas en especial, la Deconstrucción-, pero alcanza también a otros sectores implicados en el estudio y tratamiento de los textos de forma institucional como la crítica literaria o la enseñanza de la literatura. Señala como mal endémico de nuestro tiempo la hipertrofia crítica y el crecimiento desmesurado de los estudios sobre los textos (comentarios, glosas, tesis universitarias, crítica periodística, etc.) que ha terminado por construir una verdadera malla en torno a los textos hasta el punto de impedir el acceso directo a ellos. Y lo que es peor: la abundancia de textos secundarios no se corresponde ni mucho menos con una extensión parecida del conocimiento sobre ellos; en la mayoría de los casos se trata de refritos llenos de banalidades que llegan a ver la luz gracias únicamente al aval de la institución que ampara al estudioso.

La situación se presenta, en última instancia, como una consecuencia más del gran desplazamiento experimentado por el lenguaje a partir de las corrientes estructuralistas: la conexión lengua-mundo se ha visto progresivamente sustituida por el interés hacia la constitución interior de la propia lengua y el análisis de la relación entre los componentes del texto ha desbancado al interés por la comprensión de su sentido. Los resultados, según Steiner, están a la vista: primacía casi absoluta del texto secundario y confinamiento del primario en un ámbito prácticamente inalcanzable. 
La noción de texto de U. Eco (1981: cps., 2-5) enraíza más bien, sin obviar la dimensión lingüística, en la semiótica peirceana y la triple consideración del signo por parte de $\mathrm{Ch}$, Morris. El texto aparece, pues, como una combinatoria de signos dotada de una especial densidad semántica y constitutivamente volcado en el receptor o intérprete del que reclama imperiosamente una gran voluntad cooperativa como conditio sine qua non de su actualización-interpretación. El texto se presenta, en primer término, no tanto como un almacén de información sobre el mundo sino más bien como un conjunto de estrategias o instrucciones sobre los modos de hacerse con dicha información; entre ellas cabe citar al propio autor. Se trata, pues, de un mediador entre usuarios, constitutivamente muy complejo, para cuyo funcionamiento resulta imprescindible la activísima colaboración del lector: ... un texto - afirma Eco (1981: 76) — es un mecanismo perezoso ( o económico) que vive de la plusvalía de sentido que el destinatario introduce en él y sólo en casos de extrema pedantería, de extrema preocupación didáctica o de extrema represión el texto se complica en redundancias y especificaciones ulteriores... a medida que pasa de la función didáctica a la estética, un texto quiere dejar al lector la iniciativa interpretativa, aunque normalmente desea ser interpretado con un margen suficiente de univocidad. Un texto quiere que alguien lo ayude a funcionar.

En suma, tanto Steiner como Eco han contribuido a sensibilizar a los estudiosos de la literatura no sólo de la incuestionable presencia del significado en el marco de la obra artística, sino de la importancia que reviste la colaboración del lector como condición indispensable para apropiárselo. En ambos casos el texto es sólo el medio para acceder al sentido, pero un medio determinante porque son precisamente sus estrategias, según Eco (1992: 3.5), las que hacen posible la constitución de un significado bajo la forma de mundo ficcional.

3. El desarrollo de la Teoría literaria corre parejo al desenvolvimiento de la moderna Hermenéutica filosófica, la que arranca de Schleiermacher y se prolonga hasta los tiempos actuales a través de Dilthey, Heidegger, Gadamer y P. Ricoeur, entre otros (R.E. Palmer, 2002). Esta proximidad —y la inveterada costumbre del pensamiento filosófico de hacerse cargo de la reflexión en torno a las grandes cuestiones que afectan al campo de los estudios estético-literarios- son sin duda las responsables del creciente interés de la Filosofía por intervenir en debates que, en principio, serían de la exclusiva competencia de los teóricos de la literatura. La marginación del significado en el marco de las corrientes estructuralistas (y su justificación por razones preponderantemente metodológicas), el relativismo extremo — cuando no su negación, al menos en el plano de los hechos- por parte de las escuelas postestructuralistas y, por supuesto, el peso 
de la tradición hermenéutica ha llevado a los pensadores arriba mencionados, principalmente, a postular un radical cambio de rumbo en la reflexión de los teóricos de la literatura en lo concerniente a la centralísima noción de texto y, en suma, a la concepción del papel del arte en su relación con el mundo.

Es posible pensar, en principio, que se trata de intrusismo profesional; sin embargo, la categoría intelectual de los protagonistas, su profundo conocimiento de las cuestiones sometidas a discusión y, sobre todo, los argumentos esgrimidos —en especial, por Gadamer y Ricoeur - ponen claramente de manifiesto no sólo su incuestionable competencia para participar en el debate, sino la riqueza de sus aportaciones. No se puede ocultar que el planteamiento de base responde a imperativos de orden más filosófico-antropológico que estrictamente literario, lo que no deja de constituir un importante prejuicio (en el sentido gadameriano del término). Con todo, la ausencia por el momento de una verdadera hermenéutica literaria (Szondi,1975: 73-74; Domínguez Caparrós, 2001: 160-161) vuelve estéril todo intento de mantener el campo de la literatura al margen de cualquier invasión foránea (atentaría, por lo demás, contra uno de los principios reguladores del conocimiento científico actual: la colaboración multidisciplinar). Con estas premisas paso a la exposición de las contribuciones más relevantes a un renovado concepto de texto desde una perspectiva hermenéutica.

3.1. Son varios los rasgos que, a la hora de intentar una definición del objeto de estudio, se atribuyen al texto: distanciamiento, mediación, referencia no ostensiva, densidad significativa y apertura. Los dos primeros se derivan de una concepción/visión ontológico-antropológica del lenguaje —reforzada por la Lingüística y la Teoría de la acción comunicativa - y se asientan sobre la convicción de que el lenguaje (Ricoeur, 2002: 129-130)) surge como una necesidad para hablar no de sí mismo sino de lo otro, esto es del mundo; desempeña, pues, una función claramente ancilar respecto de la comprensión de la realidad. El carácter mediador del lenguaje (y, por ende, del texto) se justifica pues, como se verá, a partir de su naturaleza transcendente, de su esencial orientación hacia el exterior.

El distanciamiento se conecta, a su vez, con el tipo de texto sobre el que se centra, por tradición y de modo casi exclusivo, la Hermenéutica en sus variadas versiones: el texto escrito. Tanto Gadamer como Ricoeur insisten en la transcendencia de este rasgo para comprender la existencia de la propia Hermenéutica. Dicho alejamiento afecta a muy variadas esferas del texto, que se relacionan, fundamentalmente, con el proceso de creación: el autor (específicamente, sus intenciones), el contexto o circunstancias de la producción, el 
receptor y, por supuesto, el mundo básico o (convencionalmente) real. Como es fácil comprender, las consecuencias de estos rasgos para la teoría y práctica de la interpretación son realmente enormes.

Otro de los rasgos básicos - el que alude al tipo de referencia- pone de relieve la naturaleza ficcional del texto literario. En efecto, tanto Gadamer como, sobre todo, Ricoeur hablan de una referencia específica al aludir a la propia de los textos artísticos: 'referencia no mimética' o 'referencia metafórica'. A diferencia de lo que es habitual en el marco de la lengua oral, la literatura carece, por lo dicho anteriormente, de capacidad para mostrar su referente simplemente porque éste - en cuanto al texto narrativo y dramático esta tesis es suscrita también por K.Hamburger (1961: 96-101) - no preexiste al acto de creación y ha de verse como resultado de un proceso de producción imaginaria.

Finalmente, lo peculiar del lenguaje en forma de texto es la muy especial carga significativa que asume. A ello aluden, como se ha visto, tanto los teóricos de la literatura - destacan I. Lotman y S.J. Schmidt- como los representantes de la Hermenéutica ya mencionados. Se trata, en primer término, de una consecuencia del distanciamiento y la ambigüedad subsiguiente (Lledó, 1998: 49-50, 59-60), de la naturaleza sígnico-simbólica del texto artístico (Lotman, 1970: 3436), del primado del sentido característico del lenguaje poético y de la centralidad que asume la palabra en el interior del discurso literario y la plurivocidad que despliega en su seno (Gadamer, 2002: 338-340).

3.2. Aunque desde posiciones distintas, el rasgo del distanciamiento es objeto de análisis por parte de P. Ricoeur y E. Lledó y sus conclusiones tienden a coincidir (al menos, parcialmente). Lledó (1998:18ss) parte del famoso pasaje de Fedro, en el que, por boca de Sócrates, se narra la entrevista entre el dios Theuth, inventor de varias artes, y Thamus, rey de Egipto, al que el primero presenta las grandes ventajas de la escritura, en especial, el de actuar como un antídoto contra el olvido. Esta afirmación provoca inmediatamente la tajante respuesta de Thamus: Pues este invento dará origen en las almas de quienes lo aprendan al olvido, por descuido del cultivo de la memoria, ya que los hombres, por culpa de su confianza en la escritura, serán traídos al recuerdo desde fuera, por unos caracteres ajenos a ellos, no desde dentro, por su propio esfuerzo. Así que, no es un remedio para la memoria, sino para suscitar el recuerdo lo que es tu invento. Apariencia de sabiduría... Al margen de los excesos a que conducen muchas veces las afirmaciones platónicas, la postura del filósofo griego da en el blanco en los rasgos que separan las dos modalidades básicas de la expresión verbal: el paso del código oral al escrito implica en el primero la 
pérdida de importantísimas señas de identidad como son la sonoridad (silencio), la inmediatez (distancia), la presencia (ausencia, olvido) e incorpora la inevitable necesidad de la interpretación para recuperar, sólo en parte, los vestigios del contexto original (autor, intenciones, etc.).

Para Lledó (1998: 29-31, 149-161; 1992: 27-32) las privaciones que sufre el lenguaje al pasar por el tamiz de la escritura se ven ampliamente compensadas por su capacidad no sólo para almacenar todo tipo de mensajes sino, sobre todo, para potenciar el sentido. Lo que para Platón no es más que un pálido reflejo del discurso oral $-\mathrm{y}$, por tanto, una forma vicaria y precaria, además de silenciosa — reúne en sí dos caracteres aparentemente contradictorios como son memoria y olvido: el presente de la vivencia y el pasado del recuerdo (el texto vive únicamente en el interior del lector y, al mismo tiempo, arrastra vestigios importantes del tiempo de su producción como grafías, construcciones lingüísticas, visión del mundo,etc.). La escritura, en suma, es la presencia, aparentemente atenuada, de una ausencia en más de un sentido; lo es respecto de la oralidad y de lo evocado por el sentido.

P. Ricoeur (V. Balaguer, 2002) alude asimismo al distanciamiento constitutivo del discurso escrito en términos similares a los ya mencionados, pero va más allá; según él, este fenómeno no sólo afecta a la interpretación de los textos — de hecho, es la condición para su comprensión-, sino que implica cambios profundos en los modos de concebir el funcionamiento del esquema de la comunicación. En primer lugar, es preciso señalar que la relación entre hablante y oyente no es simétrica respecto de la que se establece entre el autor y el lector; en la escritura se lleva a cabo una doble ocultación: la del lector en el acto de producción y la del autor en el de recepción. Y este hecho tiene importantes repercusiones, por la indeterminación del sentido a que da lugar, sobre la interpretación de los textos: En efecto, la relación «escribir-leer»—señala Ricoeur (1986: 128-129) — no es un caso particular de la relación «hablar-responder». No se trata de una relación de interlocución, ni de una forma de diálogo. No basta con decir que la lectura es un diálogo con el autor a través de su obra. Hay que señalar que la relación del lector con el libro es de una naturaleza completamente distinta. El diálogo es un intercambio de preguntas y respuestas, y no existe un intercambio de este tipo entre el escritor y el lector. El escritor no responde al lector. Más bien, el libro separa las vertientes del acto de escribir y del acto de leer, que no se comunican entre sí. En realidad, la transcendencia de este rasgo es tal que termina por afectar, de un modo u otro, a todos los demás.

Gadamer insiste en que el lenguaje literario es un lenguaje literal, esto es, reproducible en sus propios términos, e incluso en su 'sonoridad' (al menos, 
mentalmente). La importancia que el material verbal adquiere en su interior exige del lector una atención especial hacia el lado físico de la lengua, independientemente de la función comunicativa: Así adquiere la palabra su autopresencia plena en el texto literario. No se limita a hacer presente lo dicho, sino que se presenta a sí misma en su realidad sonora ... la autoaparición de cada palabra en su sonoridad y la melodía del discurso también son relevantes para el contenido (2002: 339). Por lo demás, el texto literario no es transcripción de un discurso previamente pronunciado y este hecho es garante de su autonomía. Entre el texto literario y la escritura la referencia es recíproca: no son sino que significan y su existencia sólo es verificable en el acto de recepción (2002: 343).

Finalmente,y haciéndose eso de estas ideas, M. Valdés (1995: 34-38, 40) alude a cinco consecuencias que tiene para el discurso el uso de la escritura: fijación en el tiempo y disponibilidad en cuanto a su recuperación, donación de una dimensión histórica y vinculación con otros textos escritos de la misma naturaleza, hacer posible el análisis detallado del texto, alejamiento del lector del acto de producción y, en última instancia, sustitución del diálogo por la redescripción de la realidad. Este último rasgo resulta fundamental en la definición de lo que es un texto: un discurso escrito al que se le ha reconocido su capacidad de redescripción. Así, pues, continuidad de la forma, historicidad y legibilidad constituyen los tres grandes rasgos del texto.

3.3. Mediación: el segundo de los rasgos mencionados, ofrece, para Ricoeur, algunas respuestas fundamentales a cuestiones de tanta relevancia como las que se refieren al lugar y cometidos del texto y en su exposición el autor extrae los argumentos de ámbitos y disciplinas realmente diversos: epistemología, lingüística, retórica, teoría de la recepción, hermenéutica filosófica, antropología, etc.

El primer apoyo lo ofrece el esquema básico de la comunicación: el destino del mensaje-texto es mediar entre el emisor y el receptor; con todo, no conviene olvidar que este planteamiento responde preponderantemente a la realidad de la lengua oral y una definición de texto que pretenda ser válida para los productos literarios ha de ofrecer una sólida argumentación suplementaria (a la vista, sobre todo, de la existencia de corrientes tanto teóricas como creativas reivindicatorias del carácter autotélico de la literatura, de la legitimidad de un interés preferente por la forma o el caràcter autoexpresivo de la lírica ). Por lo dicho en el apartado anterior no conviene olvidar, además, que la comunicación oral no constituye un réplica sin más de la escrita.

Aunque la noción de mediación se encuentra, de un modo u otro, implícita en todos los que han tratado este asunto, es P. Ricoeur el que lo ha desarrollado más 
detenidamente y con una argumentación más solvente. El texto aparece integrado, en primer lugar, en una secuencia temporal situándose, según el autor, entre el antes y el después, lo que le precede y lo que le sigue, en más de un sentido. Esta estructura - que más que temporal es epistemológico-ontológica- se encuentra en la base de una concepción no sólo del texto, sino de la naturaleza misma de la literatura: la teoría de las tres mímesis. El texto procede del mundo por cuanto la realidad configurada en él (Mímesis II) se halla prefigurada en la realidad mundana (Mímesis I ) y en ella tienen su origen las condiciones que facilitan su inteligibilidad. La comprensión del texto narrativo — que es al que apuntan todas las referencias de Ricoeur (1987: 117-160)— requiere el conocimiento previo de lo que es una acción en el ámbito del quehacer humano y cuáles son los elementos que la integran: actantes, objetivos circunstancias, ideas, etc.

Ahora bien, una vez aclarado el papel del texto respecto del primer término de la intermediación, es preciso abordar el análisis del segundo o después de su labor mediadora. Se alude aquí a lo que el autor denomina Mímesis III, que coincide con el momento de la refiguración y que se materializa a través del proceso de lectura; en ella se lleva a cabo la intersección de dos mundos: el mundo del texto y el mundo del lector. En suma, tanto el origen como el destino del texto convergen en un punto: el mundo; en un caso, como material, y en el otro, como vivencia o experiencia estética.

El antes y el después se aplica también -y las referencias aristotélicas son una vez más inevitables- al plano compositivo: el texto funciona como mediador entre los materiales - lo que, técnicamente, se denomina red conceptual: agentes, circunstancias, objetivos, ideas, etc.- y su configuración en el marco de la trama.

Tanto Gadamer (2002: 333-337) como Hirsch, Jr. (1997: 139, 158) o Lledó (1998: 154, 158) insisten en la naturaleza mediadora del texto respecto del sentido. Para el primero, el texto no es un objeto dado, sino una fase en la realización de un proceso de entendimiento y sólo merece tal nombre el que tiende a facilitar la labor de comprensión (de ahí la exclusión de este ámbito de aquellos - para los que se reservan otras denominaciones como antitextos, pseudotextos o pretextos- que ocultan, rehúyen o enmascaran el sentido). Hirsch afirma, por su parte, que un texto es sólo una oportunidad para el sentido y añade que el texto es en sí mismo una forma ambigua carente de la conciencia en la que reside el sentido. Ideas similares pueden encontrarse en Lledó (1998: 87-88), aunque su formulación pueda resultar aparentemente contradictoria respecto de lo expresado por Ricoeur. Según el autor, no hay nada antes ni después del texto, 
nada objetivo que no pase por el lector: el antes del texto, el autor, queda disuelto en su letra y el después se confunde con sus múltiples y variadas recepciones.

3.4. La definición del tipo de referencia propio del texto literario es un asunto al que, de un modo u otro, aluden todos los investigadores, pero muy especialmente Ricoeur. Definida en términos generales, la referencia es aquello de lo que trata el texto; existen, en principio, dos modos generales de referirse a algo desde el lenguaje: uno el propio de la oralidad, y otro, el característico de la lengua escrita y, mas específicamente, literaria. La primera, se caracteriza por la función referencial deíctica, mientras que lo específico de la segunda es la función referencial no ostensiva.

En la lengua de uso más que de referencia a la realidad es preciso hablar de mostración o designación ostensiva de la misma a través, fundamentalmente, de los deícticos personales y espacio-temporales. Así, pues, la lengua oral tiende a señalar directamente aquello a lo que se refiere. No ocurre lo mismo en el texto escrito y, específicamente, en el de naturaleza ficcional; en él se lleva a cabo la suspensión de la referencia de primer grado - sencillamente, porque no hay nada que mostrar: no hay un mundo previo - pero se potencia enormemente la referencia no ostensiva (Ricoeur, 2002: 130-131; 1980: 308-343). El lenguaje, las palabras, dejan de servir a una realidad preexistente; no designan sino que proyectan un mundo, el mundo del texto. Es algo a lo que Gadamer (2002: 344) — quien, por cierto, también se refiere a la suspensión de la referencia mimética a la realidad - alude bajo la denominación de el eso del texto y tanto Dilthey como Heidegger designan Mundo del Texto; para Ricoeur (2002: 107, 203) lo que el texto despliega delante de sí es un mundo posible o, lo que es lo mismo, la propuesta de un mundo que yo podría habitar (la alusión no puede ser más aristotélica).

Si la referencia del texto escrito-ficcional no es ostensiva, ¿cuál es su naturaleza? En su respuesta el autor vuelve a mencionar a Aristóteles, aunque completando su postura con otras más recientes. La referencia literaria es una referencia metafórica: lo que hace la ficción es presentar el mundo con otros ojos - esto es, con un lenguaje diferente, traslaticio- llevando a cabo una redescripción del mismo: ...la ficción es la vía más idónea para la redescripción de la realidad, y que el lenguaje poético opera, por excelencia, lo que Aristóteles, al reflexionar sobre la tragedia, llamaba mímesis de la realidad; en mythos efecto, la tragedia no imita la realidad sino en la medida en que la recrea mediante una 'fábula', que llega a la esencia más profunda de dicha realidad (Ricoeur, 1987: 108). 
Estrechamente unida a la cuestión de la referencia está el debate sobre la inmanencia o transcendencia del texto. En principio, el alegato a favor de la suspensión de la referencia de primer grado podría inducir a pensar que la cuestión del significado habría de resolverse de puertas adentro, es decir, en el ámbito de la inmanencia textual; la construcción de mundos imaginarios (gracias a las estrategias textuales) abona aparentemente esa impresión. Sin embargo, nada más lejos de la verdad, según Ricoeur (1987: 179-180; 1996: 864-900), y son varias las razones que avalan esta suposición; de acuerdo con la distinción de Frege, puede aceptarse que el sentido del texto es determinable internamente, pero en modo alguno su significación. Básicamente, por lo dicho al tratar sobre la teoría de la tres mímesis: el texto literario se configura a partir de una competencia compartida respecto de lo que es e implica la acción humana y se orienta esencialmente hacia unos destinatarios. Así, pues, las condiciones de inteligibilidad del texto se encuentran fuera de él y enraízan en una realidad mundana que rebasa ampliamente los límites del texto; y algo similar cabe decir respecto de su destino final. Se mire por donde se mire la vocación del texto es transcenderse a sí mismo.

En este sentido es básica la distinción que, apoyada a su vez en la de Dilthey entre explicar y comprender, permite a Ricoeur (2002: 127-147, 149-168), no sólo reconocer - frente al autor alemán - el carácter complementario de ambos conceptos, sino, sobre todo, correlacionarlos con dos dimensiones fundamentales del texto: la dimensión semiótica y la dimensión semántica. La primera se interesa por el texto en cuanto combinatoria de signos regida por determinadas normas, de cuyo estudio se ha ocupado brillantemente la narratología (especialmente, la francesa) estructuralista. Sin embargo, este enfoque, de cuya legitimidad nadie puede cabalmente dudar, resulta insuficiente porque limita sus intereses al plano interno del texto, dejando sin explicación las relaciones del texto con su contexto y, más específicamente, con su referente. Es algo que surge espontáneamente en cuanto se toma en consideración la dimensión semántica, es decir, en el momento en que uno se interroga sobre el sentido del mundo que el texto lleva en su interior y se despliega ante los ojos del lector en el acto de lectura. En suma, inmanencia y transcendencia han de combinarse inevitablemente en el trabajo con el texto, si se pretende abarcar todas las fases y facultades implicadas en el arco hermenéutico: la razón, la imaginación, la sensibilidad, etc. Comprender un texto es mucho más que desmenuzarlo para poner al descubierto sus interrelaciones; es preciso dejarse llevar por el texto en la dirección abierta por el mundo que lleva dentro.

3.5. Como era de esperar, para los representantes de la Hermenéutica la definición del texto pasa por el meridiano del sentido. En ello insiste Gadamer 
(2002: 329, 340-341), el cual alude al texto como concepto hermenéutico y esencialmente destinado a la interpretación (que es inseparable de la noción de texto y fundamento de la ampliación experimentada por éste durante los últimos tiempos). Este hecho es particularmente evidente en el caso del discurso literario, donde el primado del contenido constituye una realidad incuestionable. Más radical es la postura de Hirsch (1997: 139) quien, como se vio anteriormente, asigna al texto un papel puramente ancilar: se trata simplemente de una condición necesaria para la aparición del sentido, ya que los verdaderos artífices de la significación no son los textos sino sus lectores.

De acuerdo fundamentalmente con Gadamer - $\mathrm{y}$ frente a Hirsch - Ricoeur (2002: 144, 147, 186-187, 203) afirma la preeminencia, en términos hermenéuticos, del texto respecto del hablante o autor: Lo que se ha de comprender en un relato no es en primer lugar al que habla detrás del texto, sino aquello de lo que se habla, la cosa del texto, a saber, el tipo de mundo que la obra despliega de alguna manera delante del texto (Ricoeur, 2002: 155). Dicho mundo es definido como la pluralidad de referencias a las que remite el texto o, lo que es lo mismo para el autor, como modos posibles de ser (2002: 174), fraguados por la imaginación y proyectados a través de las estructuras textuales y que han de interpretarse como alternativas o nuevas maneras de estar en el mundo. A la luz de las tesis de Ricoeur, que se han ido exponiendo en lo que precede - en especial, las referentes al carácter instrumental del lenguaje (respecto del mundo) y a la naturaleza envolvente de la dimensión semántica del texto y, por consiguiente, de la comprensión en relación con la explicación-, el texto se presenta para el autor como una realidad henchida de significado a la espera de receptores que se lo apropien. Ahí culmina el proceso de la interpretación, que es un proceso circular, pero en modo alguno un círculo vicioso. Desde esta perspectiva, son dos, fundamentalmente, las violencias a las que se puede someter un texto: una, negar su carácter plural en términos interpretativos, y otra, afirmar que las interpretaciones posibles son ilimitadas. Es éste un punto en que coinciden las posturas de Ricoeur $(2002: 186-187,189)$ y del Eco de Los límites de la interpretación (1990: 121-122, 133, 141).

3.6. La apertura, último rasgo del texto, se encuentra sin duda prefigurado, al menos en uno de sus aspectos más importantes, en la noción de referencia. Ésta implica, como se ha visto, una superación del enclaustramiento del texto por exigencias del mundo al que inevitablemente remite. Pero, la apertura puede también argumentarse desde otras perspectivas, algunas ya mencionadas al tratar, por ejemplo, de la mediación como rasgo diferencial del texto. Éste se abre, pues, al exterior como exigencia, en primer lugar, del referente o mundo que 
lleva en su interior y, a continuación, como demanda inesquivable de su labor mediadora entre mímesis I (realidad prefigurada) y mímesis III (realidad refigurada). Existen dos razones más para apoyar esta apertura: la primera, alude a la dimensión retórica del texto y la segunda, al entronque esencial entre lenguaje y subjetividad, según E. Benveniste. Que el texto se dirige a un interlocutor sobre el que desea producir un determinado efecto (placer estético, crítica, denuncia o defensa de una determinada situación o ideología, etc.) es algo postulado, sobre todo, por corrientes como la Estética de la recepción o la Pragmática lingüístico-literaria.

En cuanto a la conexión profunda entre lenguaje y subjetividad son las ideas de Benveniste (1974: 179-187; 1977:70-91), complementadas con las de G. Genette (1972) en torno a la categoría de voz, las que inspiran los argumentos de Ricoeur. Definida la subjetividad como la capacidad del hablante para postularse como sujeto y la enunciación como la movilización del lenguaje al servicio de las necesidades del emisor, el linguista francés afirma que, a través de los deícticos personales y afines, el discurso facilita no sólo la conexión con una determinada situación comunicativa sino, sobre todo, con la conciencia del enunciador. La categoría genetteana de voz es invocada en este momento por Ricoeur (1987: 177180) para ratificar la estrecha relación entre enunciación y enunciado, entre quien enuncia en la literatura y la conciencia de quien crea en la vida; en suma, entre arte y vida, ficción y realidad. El tiempo-duración o tiempo de la conciencia es donde se manifiesta de un modo palpable el contacto entre texto y subjetividad. Así, pues, por diferentes caminos y con argumentos muy variados mantiene Ricoeur la defensa a ultranza de la inevitable apertura del texto al mundo.

4. Resulta bastante obvio que, cuando disciplinas como la Hermenéutica filosófica, la Semántica lógica y la Teoría literaria aluden al significado, se están refiriendo, aun empleando los mismos términos, a realidades a veces muy diversas. Es lo que ocurre, sin duda, cuando se revisan las posturas de las corrientes teórico-literarias en sentido estricto - excluidas las inmanentistas- y las surgidas al calor de la Hermenéutica filosófica. En el primer caso, el significado se considera un componente, plano o nivel de la estructura de la obra artística, mientras que en el segundo, el significado constituye un elemento nuclear y vertebrador de la estructura, además de representar al mundo en el seno del texto. Todo conspira en él, según sus defensores, a poner en pie un sentido para cuya comprensión no bastan los códigos estrictamente literarios; es preciso convocar al mundo como parte de una competencia sin la cual el problema de la comprensión se volvería realmente insoluble, porque, insisto, la obra se considera portadora de un significado en cuya constitución interviene la realidad entendida como un saber compartido 
por el emisor y el receptor. El mundo aporta, pues, las condiciones de inteligibilidad del texto tanto desde la perspectiva de su producción como, sobre todo, de su recepción. Sólo el segundo momento, el de la configuración textual, atiende a la constitución interna de la obra literaria en cuanto activación de una serie de códigos que hacen posible la plasmación de un mundo imaginario: los genéricos, en primer término, pero también temáticos, retóricos, simbólicos, de la tradición, además de los específicos de cada autor, etc.

Del lado de la teoría literaria es preciso reconocer la existencia de propuestas cada vez más sensibles al significado de los textos. Es el caso —al margen de posturas como la Psicocrítica, la Poética de lo imaginario o la Deconstrucciónde la Escuela de Tartu (Lotman) o planteamientos cercanos a la antropología cultural (Greimas). Pero incluso en estos autores el análisis del significado se ajusta básicamente a los postulados del estructuralismo: en el caso de Greimas $(1971,1973)$ acudiendo también al modelo de la gramática generativa - lo que le permite diferenciar diversos estratos en la producción del texto narrativo literario o folclórico-, mientras que lo que a Lotman le interesa es destacar la enorme capacidad informativa y modelizadora de los textos artísticos. Es preciso reconocer, por lo demás, que tanto uno como otro defienden la permeabilidad del texto a códigos o elementos no artísticos. Para el estudioso francés, la conexión del texto con valores extraliterarios se demuestra palmariamente desde el momento en que las acciones que forman parte de una narración son interpretables a partir de las mismas etiquetas con que son designadas en la vida real - la trampa o el engaño, el contrato, la promesa, etc. - y conectan con códigos axiológicos socioculturales. Para Lotman, se trata de una realidad bastante obvia desde el momento en que se define el texto como realidad modelizadora del mundo y, también, desde la consideración de cómo los vaivenes socio-culturales (en sentido amplio) e ideológicos terminan repercutiendo sobre los fenómenos artísticos. En suma, tanto en un caso como en el otro, es el texto - sus estructuras, organización y capacidad informativa - el que acapara toda la atención y no la interpretación, a pesar de los alegatos a favor del significado textual.

Desde otra perspectiva, L. Dolezel (1997: 87-90) afirma que es el texto -y, más específicamente, las estrategias textuales - el que permite la plasmación de los productos forjados por la imaginación y, en definitiva, la construcción de los mundos posibles de la literatura. Su análisis es el que hace posible el conocimiento no sólo de la naturaleza de los mundos ficcionales, sino de las relaciones que mantiene con el mundo de la experiencia, entre otras consideraciones. Eco (1992: 235) — que comparte la doctrina de Dolezel respecto de los mundos ficcionales - insiste, a su vez, en que el texto demanda de sus receptores — del 
Lector Modelo, para ser más precisos- la máxima colaboración al servicio de una recepción provechosa, esto es, como condición indispensable para poder habitar y, en suma, disfrutar, de dichos mundos. Así, pues, desde presupuestos diversos se afirma que los textos son realidades cargadas de sentido, que ponen en pie mundos de ficción, es decir, opciones de mundo que yo podría habitar y en este punto vienen a converger las propuestas de los autores mencionados con las de Ricoeur y Steiner: existe en el texto una presencia real, un algo, que coincide con lo que, desde otros puntos de vista, también se denomina mundo del texto.

En los trabajos inspirados por la Pragmática del discurso se han producido notables avances en la dirección preconizada por la Hermenéutica. Tanto van Dijk (1995: 290-344) como Schmidt se refieren a las implicaciones semánticas de las estructuras textuales, abordando incluso la cuestión de la comprensióninterpretación de los textos. Sin embargo, el plano que más preocupa es, además del de la generación textual, todo lo concerniente a la adecuación (en términos pragmáticos) del texto al contexto. Schmidt (1987: 23-27) sí se ocupa, sin embargo, del problema de la interpretación/comprensión en un trabajo en el que se aborda la cuestión desde una perspectiva constructivista rigurosamente científica. Alude a ella como un proceso mental de constitución del significado, insistiendo al mismo tiempo en la polisemia del concepto de interpretación y concluye: La interpretación como actualización o vitalización de autores y de textos posee productivas funciones culturales en el sistema literario y no, sin embargo, en el sistema científico de la ciencia literaria (1987: 26).

Puede muy bien afirmarse que sólo el advenimiento de la Estética de la recepción —en especial, la contribución de H. R. Jauss-y el esfuerzo de individualidades como la de U. Eco ayudaron a cambiar el signo de la situación. El interés por el efecto del texto sobre el receptor contribuyó en gran medida a centrar la atención sobre el sentido de los textos en cuanto objetivo último de los lectores. Pero, aun siendo muy importante el avance, no se va mucho más allá — con la excepción de Eco- de la consideración del sentido como una realidad lagunar (Iser, 1987: 222ss), del análisis de la experiencia estética o los reajustes que va experimentando a lo largo del tiempo al verse confrontado con diferentes receptores (Jauss, 1971: 71-114; 1986: 93-184). Es preciso reconocer el interés del autor italiano por los supuestos que subyacen a la interpretación así como por la variedad de actitudes que se aprecian en su ejercicio (Eco, 1992: caps. 1-3).

Desde presupuestos más o menos diversos como el psicoanálisis (Psicocrítica), la antropología de la imaginación (Poética de lo imaginario), la crítica a la metafísica de la presencia — sin entrar en otras como las representa- 
das por los Estudios culturales, postcoloniales, feministas, etc.- se viene desarrollando sistemáticamente (en algunos casos, casi exclusivamente) una incansable actividad interpretativa con resultados también dispares. Aportaciones muy notables hay que anotar en el haber de la Escuela de Ginebra, así como en las efectuadas desde los trabajos de la Poética de lo imaginario: tanto en una como en otra es preciso reconocer los enormes esfuerzos realizados en pro de una teoría y práctica de la interpretación literaria (García Berrio, 1985, 1989, 1999).

Es algo que no es posible apreciar en los trabajos de la Deconstrucción a causa, principalmente, de su negativa (de hecho) a reconocer la presencia de un significado en los textos — de él no quedan más que huellas apenas advertibles y, en suma, por la supuesta desvinculación entre los textos y el mundo (Steiner, 1991: 119-166).

La gran aportación de la Hermenéutica - y, específicamente, de Gadamer y Ricoeur - consiste en haber recordado a los teóricos de la literatura que la plena inteligencia del texto pasa inevitablemente por la incorporación pleno iure del significado al análisis de los textos. Desde supuestos ontológicos, epistemológicos, lingüísticos y estéticos se insiste en que el proceso realmente comprehensivo de un texto no puede detenerse en el plano puramente formal, sino que es preciso dar pasos adelante en la dirección hacia la que apunta el sentido. Esta dirección encamina necesariamente hacia el referente, esto es, el mundo que el texto porta en su interior, el cual, a su vez, remite a la realidad humana en cuanto depositaria de las condiciones de inteligibilidad que facilitan la interpretación del texto y al lector en cuanto destinatario de todas las actividades y sensaciones que el texto busca provocar en él. Son varios los puntos en los que la Hermenéutica parece haber ejercido un influjo más determinante: ha actuado de freno frente a ciertas tendencias disolventes — caso de la Deconstrucción, especialmente-, ha reafirmado otras de signo positivo como son la conexión entre literatura y vida y la importancia del lector y, finalmente, ha puesto de manifiesto la inevitable complementación entre el examen de la estructura y el análisis del sentido de los textos:

Desde el punto de vista hermenéutico —afirma Ricoeur-, es decir, desde el punto de vista de la interpretación de la experiencia literaria, un texto tiene una significación muy distinta de la que le reconoce el análisis estructural extraído de la lingüística: es una mediación entre el hombre y el mundo, entre el hombre y el hombre, entre el hombre y él mismo. La mediación entre el hombre y el mundo es lo que se denomina referencialidad; la mediación entre el hombre y el hombre es la comunicabilidad; la mediación entre el hombre y él mismo es la comprensión de sí. 
El diálogo entablado entre la Hermenéutica y la Teoría literaria dista mucho de ser estéril y parece haber comenzado a dar sus frutos, al menos en lo relativo a la necesidad de adaptar la doctrina sobre la interpretación a los condicionamientos del ámbito literario. Continúa sin duda pendiente la tarea de desarrollar una hermenéutica no sólo consistente, sino realmente sensible a las peculiaridades del fenómeno de la literatura y, en este sentido, el papel que puede desempeñar la reflexión ejercida desde ámbitos próximos — como es la defendida en este trabajo- es enorme. Al tiempo corresponde rectificar o confimar la verdad de esta afirmación.

\section{REFERENCIAS BIBLIOGRÁFICAS}

BAJTín, M. (1975). Estética y teoría de la novela. Madrid: Taurus, 1989.

Balaguer, V. (2002). La interpretación de la narración. La teoría de Paul Ricoeur. Pamplona: Eunsa.

BARTHES, R. (1964). Ensayos críticos. Barcelona: Seix Barral, 1967.

Benveniste, E. (1966 y 1974). Problemas de lingüística general. México: FCE, 2 vols. (1971 y 1977).

DiJK, T. A. van (1977). Texto y contexto. Madrid: Cátedra.

Dolezel, L. (1988). «Mímesis y mundos posibles». En A. Garrido Domínguez (ed.), 69-94.

Domínguez CAparrós, J. (comp.) (1997). Hermenéutica. Madrid: Arco/Libros.

Domínguez CAPARRós, J. (2001). Estudios de teoría literaria. Valencia: Tirant lo Blanch.

Eco, U. (1979). Lector in fabula. La cooperación interpretativa en el texto narrativo. Barcelona: Lumen.

— (1990). Los límites de la interpretación. Barcelona: Lumen, 1992.

GadAmer, G. 1986). Verdad y método II. Salamanca: Sígueme, $5^{\text {a }}$ ed. (2002).

García Berrio, A. (1985). La construcción imaginaria en «Cántico» de Guillén. Limoges, París: Trames. 
García Berrio, A. (1989). Teoría de la Literatura: la construcción del significado poético. Madrid: Cátedra.

- (1999). Forma interior: la creación poética de Claudio Rodríguez. Málaga: Ayuntamiento, Col. Aire Nuestro.

Garrido Domínguez, A. (ed.) (1997). Teorías de la ficción literaria. Madrid: Arco/Libros.

Genette, G. (1972). Figuras III. Barcelona: Lumen,1989.

Greimas, A. J. (1966). Semántica estructural. Madrid: Gredos,1971.

— (1970). En torno del sentido. Madrid: Gredos,1973.

HAMBURGe. K. (1957). La lógica de la literatura. Madrid: Visor, 1995.

HiRsch, E. D. Jr. (1972).«Tres dimensiones de la hermenéutica.» En J. Domínguez Caparrós (ed.), 138-158.

INGARDEN, R. (1931). L'oeuvre d'art littèraire. Lausana: L'Age d`Homme, 1983.

ISER, W. (1972). «El proceso de lectura: enfoque fenomenológico.» En J. A. Mayoral (ed.), 215-243.

JAUSS, H. R. (1967). «La historia literaria como desafío a la ciencia literaria.» En H. U. Gumbrecht y otros, La actutal ciencia literaria alemana. Salamanca: Sígueme, 1971.

— (1977). Experiencia estética y hermenéutica literaria. Madrid: Taurus, 1986.

Lotman, I. (1970). La estructura del texto artístico. Madrid: Istmo, 1978.

— (1996). La semiosfera I. Madrid: Frónesis, Cátedra, Universidad de Valencia.

LLEDÓ, E. (1991). El silencio de la escritura. Madrid: Espasa Calpe, 1998.

— (1992). El surco del tiempo. Barcelona: Crítica.

Mayoral, J. A. (ed.) (1987). Estética de la recepción. Madrid: Arco/Libros.

Mignolo, W. (1978). Elementos para una teoría del texto literario. Barcelona: Crítica.

- (1986). Teoría del texto e interpretación de textos. México: UNAM.

Mukarovsky, J. (2000). Signo, función y valor. Estética y semiótica del arte de Jan Mukarovsky. Barcelona: Plaza \& Janés. 
Palmer, R. E. (1969). ¿Qué es la hermenéutica? Madrid: Arco/Libros, 2002.

RICOEUR, R. (1975). La metáfora viva. Madrid: Ediciones Europa, 1980.

- (1983-1985). Tiempo y narración. Madrid: Cristiandad, 1987 (vols. I-II). México: Siglo XXI, 1996 (vol. III).

- (1986). Del texto a la acción. Ensayos de hermenéutica II. México: FCE, 2002. Se han manejado las monografías siguientes: «Acerca de la interpretación», 15-36; «La función hermenéutica del distanciamiento», 95-110; «¿Qué es un texto?», 127-147; «Explicar y comprender», 149-168; «El modelo del texto: la acción significativa considerada como un texto», 169-195.

SCHMidT, S. J. (1973). Teoría del texto. Madrid: Cátedra, 1977.

— 1984). «La auténtica ficción es que la realidad existe. Modelo constructivista de la realidad, la ficción y la literatura.» En A. Garrido Domínguez (ed.), 207-238.

SteInER, G. (1989). Presencias reales. Barcelona: Ensayos/Destino,1991.

VALDÉS, M. (1995). La interpretación abierta: introducción a la hermenéutica literaria contemporánea. Amsterdam-Atlanta: Rodopi.

Szondi, P. (1975). «Introducción a la hermenéutica literaria.» En J. Domínguez Caparrós (ed.), 59-74. 